\title{
PARAGEUSIA FOLLOWING BELL'S PALSY : A RESULT OF FAULTY RE-INNERVATION
}

BY

\author{
GEOFFREY RUSHWORTH
}

\author{
From the Neurological Research Unit, Churchill Hospital, Oxford
}

Loss of taste on the anterior two-thirds of the tongue is quite a common accompaniment of Bell's palsy and it may persist unless reasonable reinnervation takes place. Parageusia, however, is only rarely met with (Symonds, C. P., personal communication), and the following case history is that of a patient whose life was made intolerable by a strong, persistent salty taste in the right side of the mouth which came on six months after a right Bell's palsy and was associated with other evidence of faulty re-innervation.

M.J., an old lady aged 75, had an attack of "flu" in October, 1957, and in the convalescent phase began to experience dull, aching pain around the right ear and then almost three days later complete right facial paralysis. At this time, she noticed that she was unable to taste on the right side of the tongue. No herpes were noted either by the patient or by her doctors.

When seen in Oxford eight weeks later (December 19, 1957) she was an alert old lady who was very deaf. There was complete right facial paralysis and loss of taste over the anterior two-thirds of the right side of the tongue. Apart from bilateral eighth nerve deafness there were no other physical signs of disease in the nervous system.

Two months later (February 18, 1958) after attending the physiotherapy department twice weekly for electrical stimulation, there was still no voluntary movement of the facial muscles.

In May, 1958, seven months after the original Bell's palsy, the patient complained that she now had an unpleasant salty taste in the right side of the mouth which had been present for about four weeks, and the right eye tended to water profusely whenever she ate. Severe contracture of the right side of the face had occurred, and as a consequence the right eye was almost totally closed.

In October, 1958, she was admitted to the Churchill Hospital for assessment as the unpleasant salty taste was making her life intolerable; she had never liked salt and now all her food tasted very salty and the taste of unpleasant brine was always with her. She attempted to remove the saltiness by frequently washing her artifical teeth under running water. The salty taste was most intensely localized to a small region of the lower lip on the right side, and seemed to originate there. She ate very little as the salty taste now nauseated her. On $\frac{\bar{\sigma}}{\overline{0}}$ examination; the patient was an elderly, very deaf, $\overparen{\varnothing}$ bright, white-haired woman who was rather emaciated. 을 She had obvious facial assymetry, and the face was \& drawn to the right, the right eye being almost completely $\overrightarrow{ }$ closed. Voluntary movements of the face were minimal: she was unable to corrugate the forehead on the right, $\vec{\omega}$ she could close the right eye though the orbicularis oculi o was very weak, movement of the right side of the mouth was minimal, and the right platysma was also in contracture. There were associated movements between the right side of the mouth and the right orbicularis $\omega$ oculi.

Taste sensation was explored on the tongue: on the right, solutions of salt, sugar, dilute acetic acid, anel $\mathrm{O}$ quinine were not tasted. The right side of the palase also showed this abnormality, whereas the left side of palate and tongue were quite normal.

When the patient's lips, mouth, and tongue wegec painted with $1 \%$ cocaine, taste sensation was abolished ? from the left side of the tongue and palate, but the $\overrightarrow{0}$ spontaneous salty taste referred to the right side of the $)$ tongue and mouth, persisted.

The same result was obtained when the patient sucked nupercaine lozenges though now the sensations of pain and touch as well as taste were absent. It was thus apparent that the afferent impulses giving rise to the spontaneous sensation of salty taste did not originate $\mathbb{D}$ in the mouth.

During the period when the mouth was anaesthetized $\overrightarrow{\bar{\partial}}$ it was also noted that the previous continuous secretion 3 of tears from the right eye had ceased.

When $2 \mathrm{ml}$. of $2 \%$ xylocaine was infiltrated around the right facial nerve behind the ramus of the mandible, the parageusia was completely lost together with a little weakening of the already feeble musculature on that side. On another occasion an infiltration of $2 \%$ procaine 3 across the branches of the facial nerve as they emerge from the parotid gland gave identical results. TheO parageusia returned when the local anaesthetic had worn off.

Encouraged by the success of the local anaesthetic in abolishing the unpleasant salty taste, $0.1 \mathrm{ml}$. of absoluteo alcohol was injected following a successful facial block with $2 \%$ xylocaine, using the same needle which had beenos left in situ. Twenty-four hours later the patient stilh had the parageusia but thought it was less than before 
The procedure was repeated using this time $0.2 \mathrm{ml}$. absolute alcohol. Again complete abolition of parageusia was not obtained, so finally $0.4 \mathrm{ml}$. of absolute alcohol was injected near the nerve after xylocaine block. This time the patient was completely free of parageusia and still had some facial movement and could close the right eye. The secretion of tears by the right eye was much less than previously but had not been abolished completely.

At follow-up examination in February, 1960, the patient stated that the salty taste returned about one month after the injection, but was no longer intense and no longer troubled her. The facial contracture was severe, the right eye was completely closed, and voluntary facial movement on the right side was minimal. Taste sensation was still absent on the right side of the tongue.
The patient was now enjoying her food and had put on weight.

\section{Discussion}

Bell's palsy is one of the commonest nerve lesions that is seen in neurological clinics, and a study of these cases has already contributed much information on the general problem of recovery of nerve lesions in continuity. It is sometimes surprising how badly an undivided motor nerve may regenerate, and because of the sprouting and division of axons to re-innervate several different facial muscles it may produce bizarre effects on facial expression. Irrevocable functional union may take place between muscles which do not normally

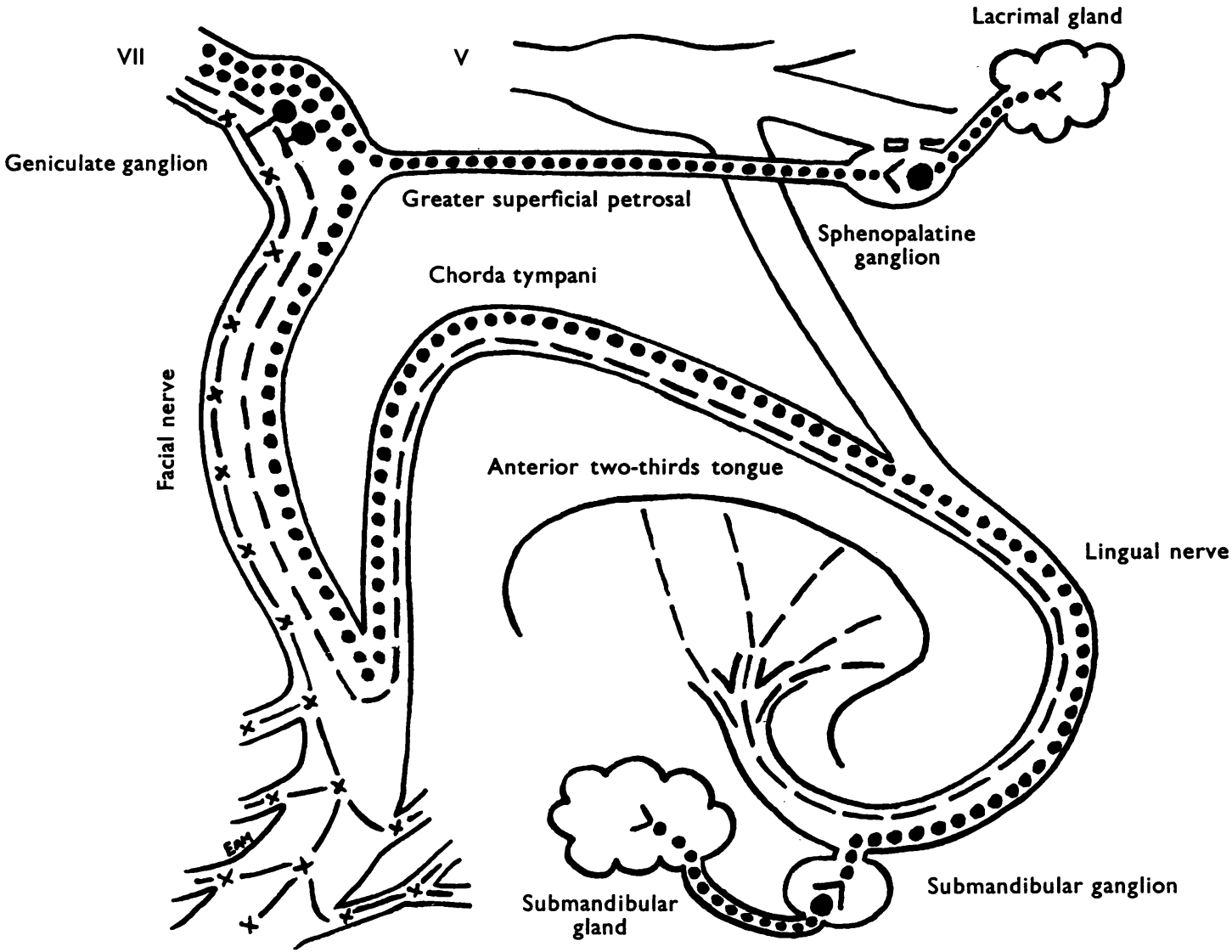

Muscular branches

Fig. 1.-A diagrammatic representation of the afferent and secreto-motor fibres of the facial nerve. The motor fibres supplying the facial musculature have been omitted for the sake of clarity.

Following a lesion of the facial nerve in the geniculate ganglia or central to it, faulty regeneration may result in linkage between the secreto-motor fibres of the lacrimal and salivary glands. This produces the phenomenon of crocodile tears. When the lesion is at the origin of the chorda tympani as it leaves the facial nerve or central to this site, parageusia may result from faulty linkage between taste and muscle afferents. 
contract simultaneously (Howe, Tower, and Duel, 1937), and an example of this linkage was illustrated by James and Russell (1951) in which the patient's smile was also accompanied by a wink. Mass re-innervation due to division of axons is not, however, restricted to the motor nerves of muscles, for the syndrome of crocodile tears (Ford, 1933; Boyer and Gardner, 1949) shows a faulty linkage between the salivary and lacrimal glands. Thus the afferent influx which usually determines a reflex stimulation of salivary secretion also now stimulates the lacrimal gland (Fig. 1). Moreover it is also probable that facial muscle efferents may also faultily re-innervate the lacrimal gland, as acetylcholine is the common junctional transmitter, and axon sprouts from large fibres will grow into the neurilemmal tubes of degenerated small fibres and vice versa (Sanders and Young, 1944, 1946). Thus with every facial movement, whether reflex or voluntary, there will also be glandular secretion. The present case showed this phenomenon, and the crocodile tears were reduced when the facial nerve was partially blocked with alcohol thus interrupting some of the efferent fibres destined for the lacrimal gland.

The afferent fibres of the chorda tympani are a relatively minor part of the facial nerve, and, according to Zotterman (1935), are unmyelinated fibres probably less than $4 \mu$ in diameter. The other known afferent component of the facial nerve is the group of proprioceptive fibres which originate in the facial musculature. It is postulated that the disability of the present case occurred because, during regeneration, fibres of the chorda tympani grew into the neurilemmal tubes of proprioceptive fibres and re-innervated the stretch receptors of the facial musculature. Thus the proprioceptive discharge passed into fibres of the chorda tympani and were interpreted as "salty taste". It was certainly demonstrated that the origin of the afferent impulses giving rise to the salty taste did not reside in the mouth though they were abolished by blocking the facial nerve over the zygoma. Unless "artificial synapses" between motor and sensory nerves can 0 occur following a nerve lesion, no other hypothesis ${ }_{0}$ than the faulty re-innervation of proprioceptors with taste fibres of the chorda tympani will satisfactorily explain the facts of this case.

\section{Summary}

A case is described of parageusia following Bell's palsy after six months.

The strong, persistent taste of salt was in the right side of the mouth and tongue from which the sensations of taste were absent.

The parageusia was unaffected by completely anaesthetizing the mouth.

The parageusia was abolished reversibly by block- $\overrightarrow{\vec{H}}$ ing the facial nerve with local anaesthetics, and $\stackrel{\rho}{\omega}$ permanently diminished by a small injection of absolute alcohol which did not entirely destroy all facial movements.

It is through the kindness of Dr. Ritchie Russell thit in this case was investigated. Dr. K. A. K. North ga退 willing assistance and I am most grateful for his help 0 and cooperation. Sir Charles Symonds, Sir Russegl Brain, and Dr. D. Taverner very kindly commented on this case and they have my grateful thanks. I am ips-c debted to my wife, Dr. Elizabeth Martin, for her criticisiog of the manuscript and for the careful drawing of Fig.

\section{REFERENCES}

Boyer, F. C., and Gardner, W. J. (1949). Arch. Neurol. Psychiat. (Chicago), 61, 56.

Ford, F. R (1933). Ibid., 29, 1279.

Howe, H. A., Tower, S. S., and Duel, A. B. (1937). Ibid., 38, 1190.

James, J. A., and Russell, W. Ritchie (1951). Lancet, 2, 519.

Samders, F. K., and Young, J. Z. (1944). J. Physiol. (Lond.), 103, Sanders, F. K., and Young, J. Z. (1944)
119. (1946). J. exp. Biol., 22, 203.

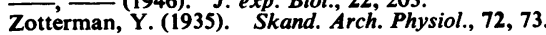

